\title{
SOFTWARE SYSTEMS FOR VISUALIZING THE CENTRIFUGAL COMPRESSOR STAGES FLOW PATH AND CREATING 3D MODELS OF IMPELLERS
}

\author{
A. A. KOTLOV ${ }^{1}$, A. A. DROZDOV ${ }^{2}$, V. B. SEMENOVSKIY ${ }^{3}$ \& K. KABALYK ${ }^{4}$ \\ ${ }^{1,2,3}$ National Technology Initiative Center for Advanced Manufacturing Technologies based on the Institute of Advanced \\ Manufacturing Technologies of Peter the Great St. Petersburg Polytechnic University Polytechnicheskaya, Russia \\ ${ }^{4}$ Lodz University of Technology, Institute of Turbomachinery Wolczanska 219/223 Lodz, Poland
}

ABSTRACT
Information about the software package for visualizing the design results of centrifugal compressor stages by the
Universal Modeling Method is presented. The programs of the Universal Modeling Method produce the optimal gas-
dynamic design of centrifugal compressors and compressor stages, determine the main dimensions of the flow path. The
software package "Digital Twin of the Centrifugal Compressor Stage" presents the results obtained in graphic form
and in the form of $3 D$ models. The user is presented with information in the form of stage drawings in the meridional
and radial planes, a $3 D$ model of the impeller and the blades' coordinates on the hub and shroud surfaces, as well as a
$3 D$ compressor stage model.
KEYWORDS: Software Systems, $3 D$ Compressor \& Centrifugal Compressor

Received: Jun 08, 2020; Accepted: Jun 28, 2020; Published: Sep 25, 2020; Paper Id.: IJMPERDJUN20201426

\section{NOMENCLATURE}

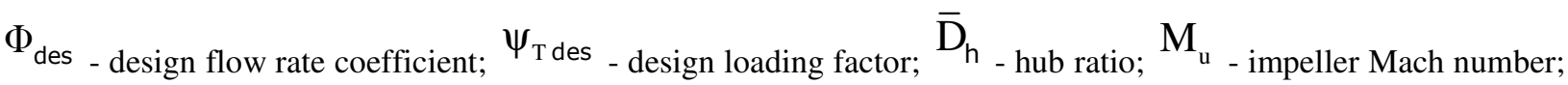
$\overline{\mathrm{D}}_{0}$ - impeller inlet diameter; $\beta_{\mathrm{blls}}^{0}$ - inlet blade angle to tangential direction at shroud; $\beta_{\text {bllh }}^{0}$ inlet blade angle to tangential direction at hub; $\bar{R}_{h}$ - hub radius of curvature; $\bar{R}_{s}$ - shroud radius of curvature; $\bar{L}_{m}$ - relative axial length of impeller; $\bar{b}_{2}$ - impeller blade height at the exit; $\mathrm{p}_{\mathrm{inl}}^{*}$ - inlet total pressure; $\mathrm{T}_{\mathrm{inl}}^{*}$ - inlet total temperature; $\mathrm{k}$ isentropic coefficient; ${ }^{n}$ - RPM; $\mathrm{Z}$ - blade number; $\bar{R}_{\text {- radius, gas constant; }} \beta_{\mathrm{b} 12}^{0}$ - exit blade angle to tangential direction.

$$
\begin{aligned}
& \bar{A}=A / D_{2} \text { - a dimension is related to an impeller diameter } \\
& \text { ABBREVIATION } \\
& \text { VD - vane diffuser; VLD - vaneless diffuser; } \mathrm{RCh} \text { - return channel }
\end{aligned}
$$

\section{INTRODUCTION}

For decades, SPbPU has been researching turbo compressors, processes and phenomena occurring in them, and designed centrifugal compressors for various purposes $[0,2]$. The results obtained in this process made it possible to create a method for gas-dynamic design and calculation of centrifugal compressors, a corresponding mathematical 
model and a software package based on it, called the Universal Modeling Method. The mathematical model is based on the model of gas flow in the flow path of a centrifugal compressor stage [3, 20 - 28]. The studies carried out at SPbPU include the analysis of the flow both in the stage as a whole and in individual flow path elements.

The programs of the Universal Modeling Method are widely used in the practice of calculating and designing centrifugal compressors and compressor. The method was applied to create a new generation of pipeline centrifugal compressors for the gas industry [4]. Taking into account all the projects completed by SPbPU, in the industry of the Russian Federation and other countries there are about 500 centrifugal compressors of more than fifty types with a total installed capacity of more than 5 million $\mathrm{kW}[3,5]$.

\section{The Main Steps of Calculation and Design of a Centrifugal Compressor Stage by the Universal Modeling Method}

Designing a centrifugal compressor stage using the Universal Modeling Method begins with calculating the basic dimensions of a stage for design parameters using the formulas of preliminary design [11, 12]. Method of preliminary design of Universal Modeling Method refers to the stages with subsonic impellers with shroud. Design parameters and range of application:

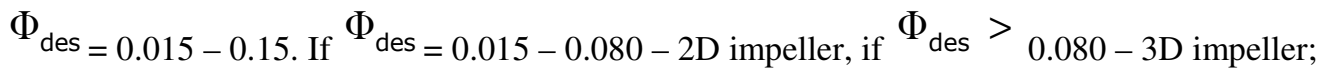

$$
\begin{aligned}
& \psi_{\text {Tdes }}=0.40-0.70 \\
& \overline{\mathrm{D}}_{\mathrm{h}}=0.25-0.40 \text { if } \Phi_{\text {des }}<0.080, \overline{\mathrm{D}}_{\mathrm{h}}=0.25-0.35 \text { if } \Phi_{\text {des }}>0.080 ; \\
& \mathrm{M}_{\mathrm{u}}<0.9
\end{aligned}
$$

The preliminary design of the 2D impeller consists of calculating the following geometric parameters:

$$
\overline{\mathrm{D}}_{0}, \overline{\mathrm{D}}_{1}, \overline{\mathrm{b}}_{1}, \overline{\mathrm{b}}_{2}, \overline{\mathrm{R}}_{\mathrm{s}}, \overline{\mathrm{R}}_{\mathrm{h}}, \mathrm{z}, \beta_{\mathrm{bl1}}^{0}, \beta_{\mathrm{bl} 2}^{0}
$$

The preliminary design of the 3D impeller consists of calculating the following geometric parameters:

$$
\overline{\mathrm{D}}_{0}, \overline{\mathrm{R}}_{\mathrm{s}}, \overline{\mathrm{R}}_{\mathrm{h}}, \overline{\mathrm{L}}_{\mathrm{m}}, \overline{\mathrm{b}}_{2}, \mathrm{z}, \beta_{\mathrm{bl1s}}^{0}, \beta_{\mathrm{bllh}}^{0}, \beta_{\mathrm{bl} 2}^{0}
$$

Determination of the size and shape of the centrifugal compressor stage flow path stator elements is carried out on the basis of the approximating equations presented in the papers $[18,19,20]$.

After preliminary design:

- according to the 3DM.023 program, the velocity diagrams of the impeller blades are analyzed and, if necessary, impeller geometry is corrected. The main provisions for assessing the impeller quality and design recommendations in inviscid quasi-three-dimensional flow programs are given in the papers $[0,15,16,17]$;

- the gas-dynamic characteristics of the preliminary design are calculated, the flow parameters in the control sections are analyzed and corrections are made to the main dimensions of the flow path;

- the set of compressor stage characteristics is calculated. 
As an example, Figure 1 shows the menu for setting design parameters in the module for preliminary stage calculation (on the left) and the menu for the program of calculating the stage gas-dynamic characteristics with dimensions obtained after the preliminary design (on the right).

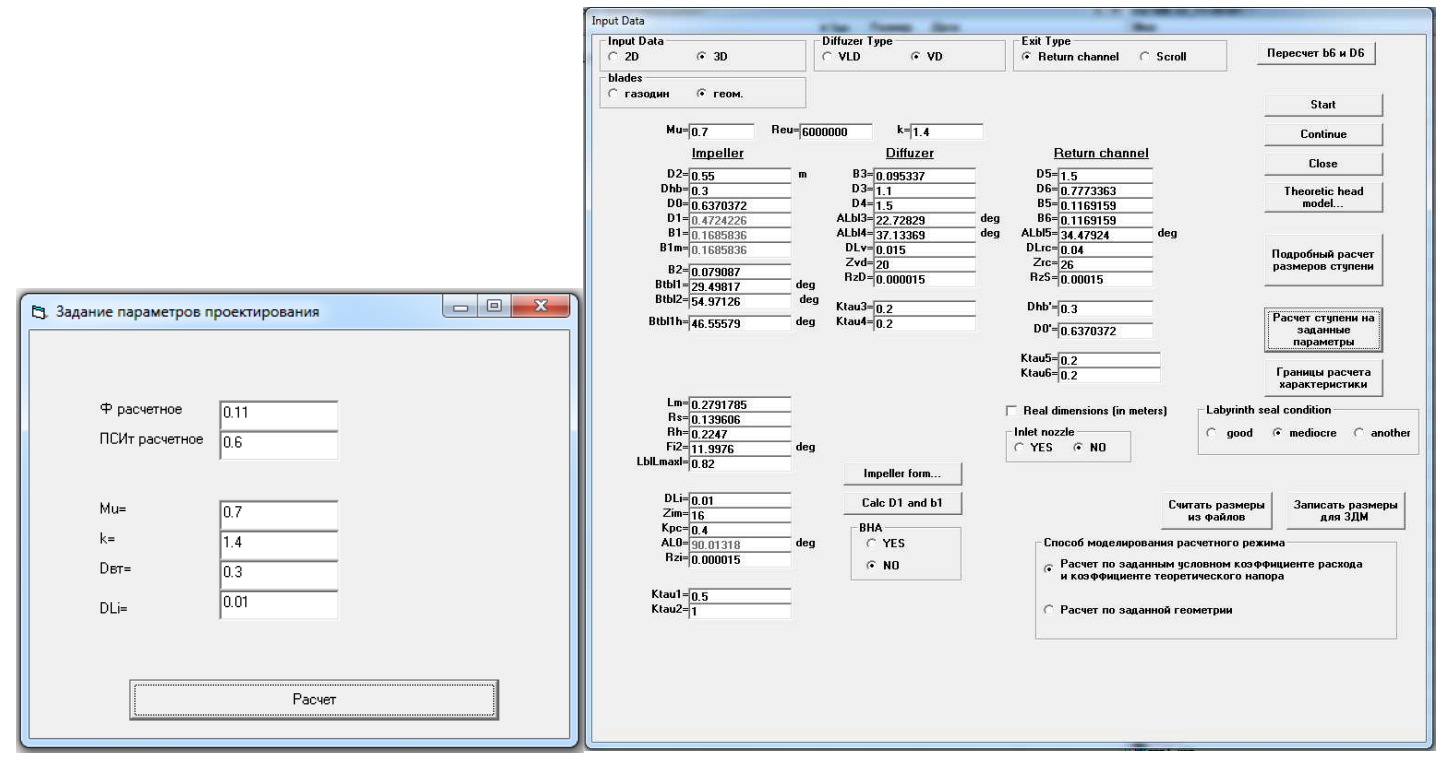

Figure 1: «OPTIM 2» Program. Model Stage with 3D Impeller+VD+RCh. On the Left are Design Parameters Menu. On the Right - Dimensions after Preliminary Design.

Pressing the button "Record dimensions for 3DM" generates the files necessary for calculating the velocity diagrams of an inviscid quasi-three-dimensional flow on the impeller blades. Figure 2 shows the velocity diagrams on three current lines of the preliminary designed impeller, obtained using the inviscid quasi-three-dimensional calculation program.

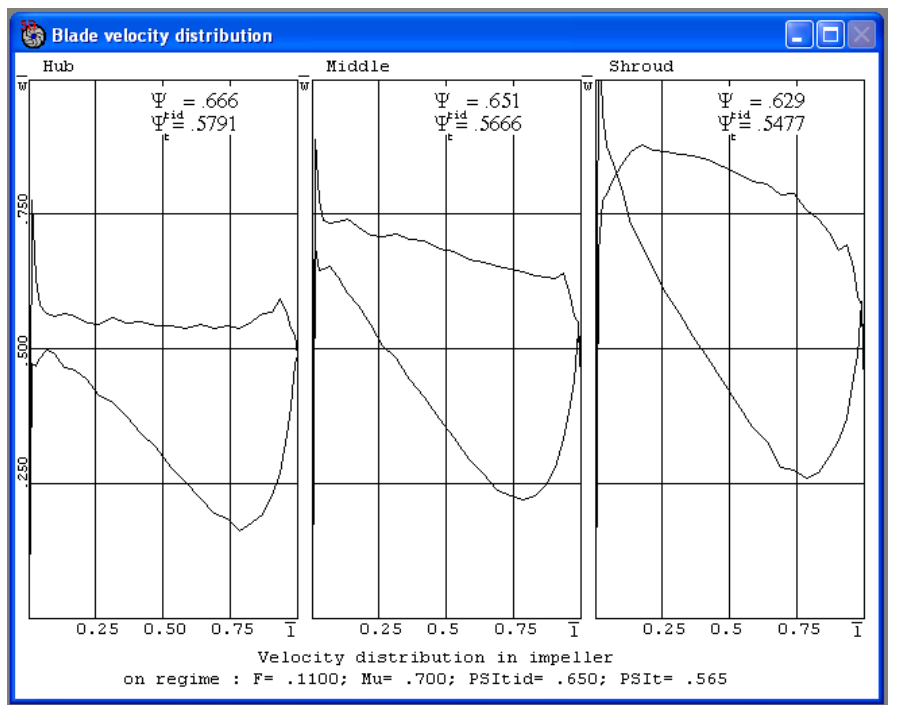

Figure 2: 3DM.023 Program. Velocity Diagrams on Three Blade-to Blade Surfaces of the Impeller Preliminary Design [15].

If necessary, the impeller dimensions are corrected in the 3DM.023 program. The diagram on Figure 2 shows in particular that the excessive negative incidence at the shroud blade -to-blade surface must be minimized one or other way. 
Customers of centrifugal compressors gas-dynamic designs require information on the parameters of the compressor at non-design flow rates. For gas turbine-driven compressors, it is usually required to calculate the set of characteristics in the range of $0.7-1.05$ of the design RPM. Programs of the Universal Modeling Method provide the ability to calculate a set of characteristics when changing any of the initial parameters $\mathrm{p}_{\mathrm{inl}}^{*}, \mathrm{~T}_{\mathrm{inl}}^{*}, \mathrm{k}, \mathrm{R}, \mathrm{n}$. When calculating the stage dimensionless characteristics, the number of variables is reduced to the similarity criteria. As an example, Figure 3 shows the set of stage characteristics when operating with $\mathrm{M}_{\mathrm{u}}=0.78$ on gases with different coefficients $\mathrm{k}=1.1,1.25,1.4,1.55$.

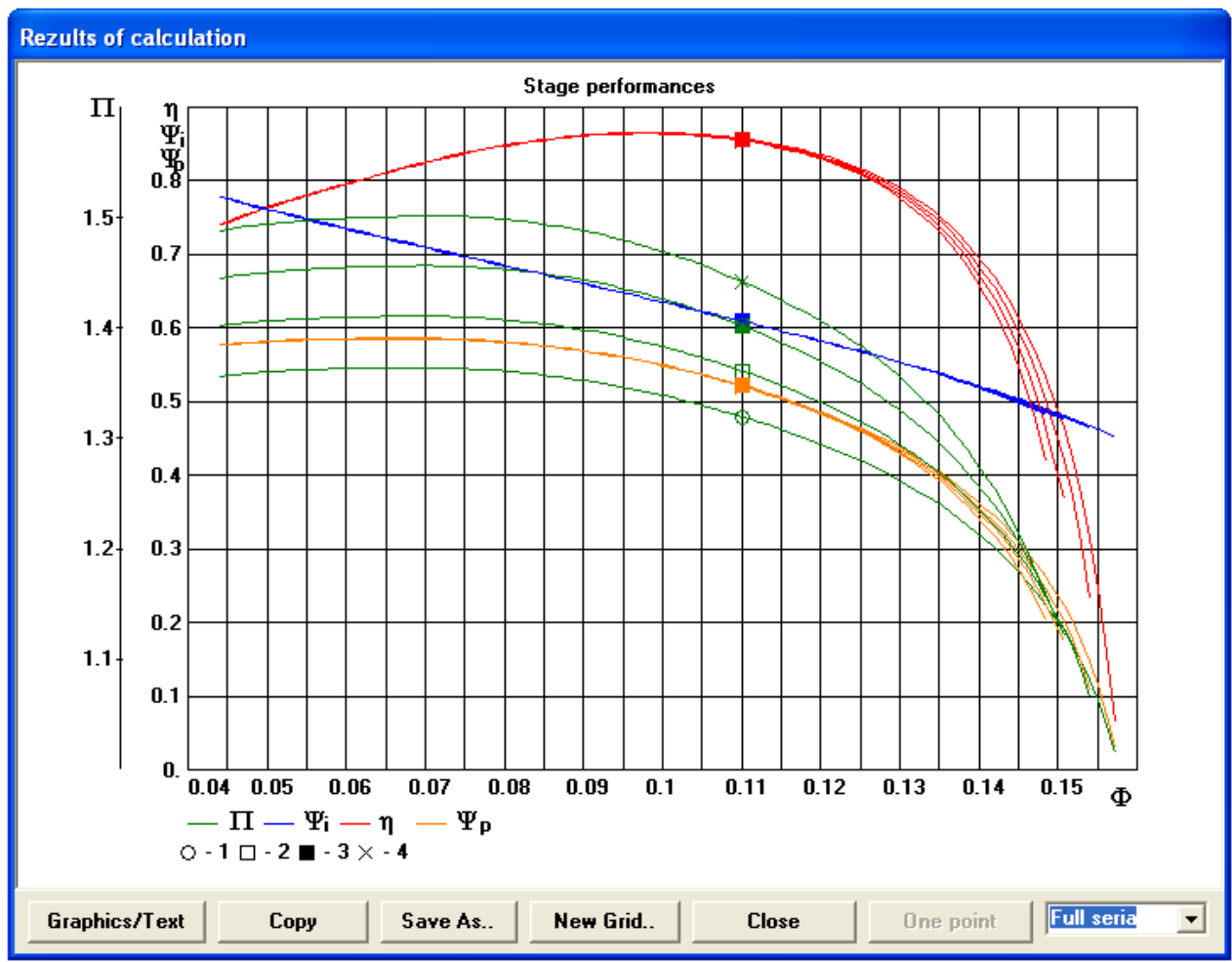

Figure 3: Characteristics of a Stage with 3D Impeller+VD+RCh when Operating on Gas with Different Isentropic Coefficients.

The design experience of the Universal modeling demonstrates the need for quick presentation of design results in a graphical form. Another important part of the research is conducting CFD-calculations. In order to automate the process of transition from the results of calculations using one-dimensional models to calculations using CFD-methods, it is necessary to present the design results in the form of 3D models. For this purpose, a set of programs "Digital twin of a centrifugal compressor stage" was developed.

\section{CENTRIFUGAL COMPRESSOR STAGE DRAWING PROGRAM}

At the first step of the process of visualizing the size and shape of the centrifugal compressor stage flow path, the program "Drawing of a centrifugal compressor stage" is used. It constructs the drawings of the stage in the meridional and radial planes both for the stage and for its elements (Figure 4).

The user has the ability to change the stage size. A number of geometrical dimensions, such as the diaphragm thickness, the meridional outlines of the flow path, the position of the trailing edge of the straightening vane, etc. adopted 
on the basis of summarizing the results of designing centrifugal compressor stages in the range of parameters $\Phi_{\text {des }}=0.015$ $-0.15, \psi_{\text {Tdes }}=0.5, \bar{D}_{h}=0.25-0.3$ [6]. If the stage design parameters differ from those indicated above, it may be necessary to change the flow path dimensions.
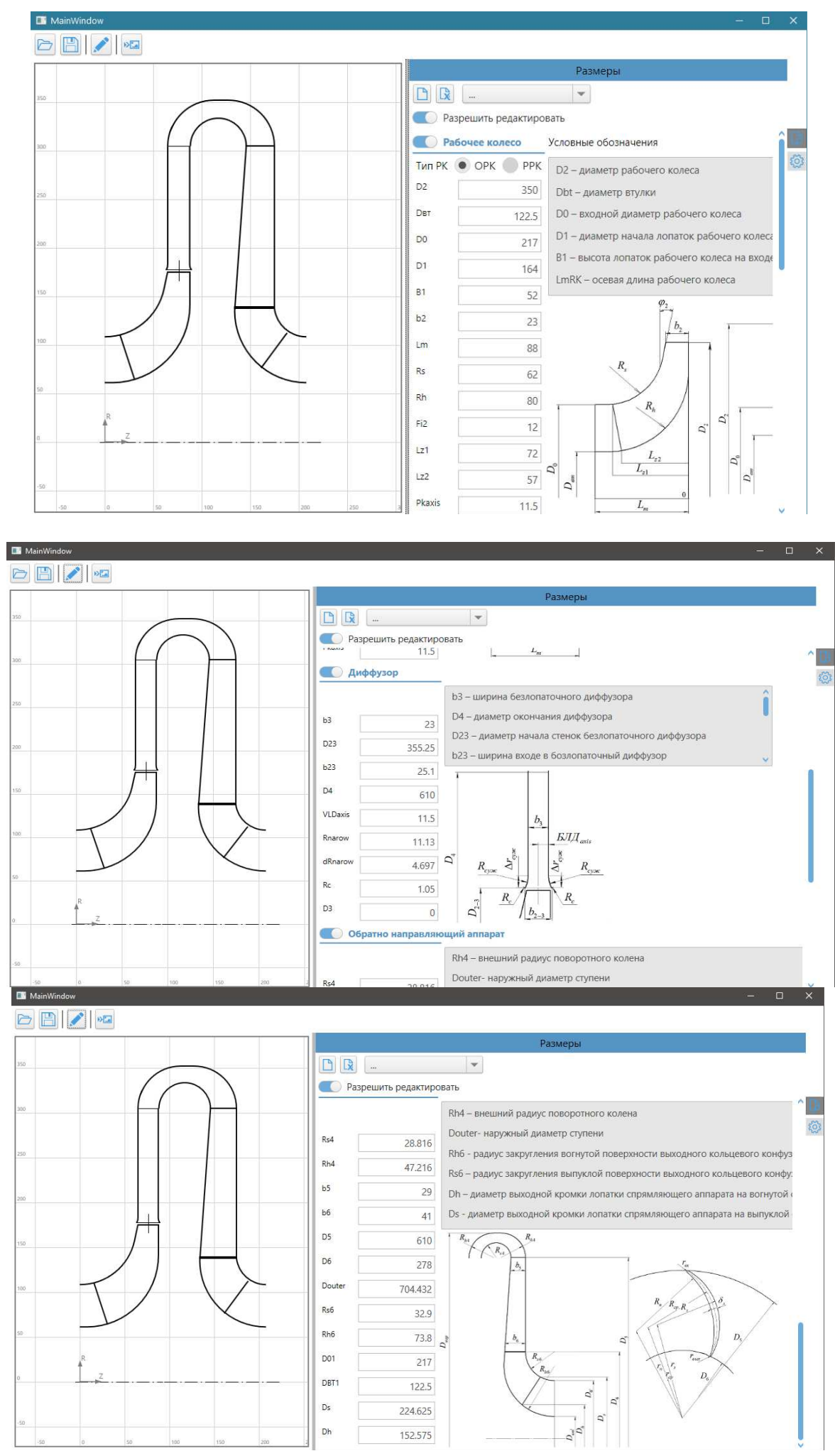

Figure 4: Examples of a Stage, VLD and RCh Drawings According to the Program "Drawing of a Centrifugal Compressor Stage". 


\section{PROGRAM FOR CONSTRUCTING A 3D MODEL OF THE IMPELLER}

Visualization and final determination of the impeller blades size is performed in the "Impeller 3D" program. Initial data for building an impeller 3D model are taken from the programs of the Universal Modeling Method [7, 8, 9, 10]. Based on the corrected dimensions, the calculation of all necessary dimensions for the construction of centrifugal stage drawings is made. The parameters of the impeller blades, which determine their shape and dimensions, are also set: the thickness of the leading edge of the blade, the length of the sharpening section of the blade leading edge, parameters a and $b$, which determine the change in the blade angle along the blade length, the outlet bulk angle. Such parameters as the bulk angle, the leading edge thickness and the length of the sharpened section are taken to be the same for impellers with different design parameters.

The program "Impeller 3D" builds a 3D model of the impeller based on this data. Depending on the option chosen at the design step, a model of 3D or 2D impellers is built. Figure 5 shows a 3D model of the 3D impeller with and without a shroud.
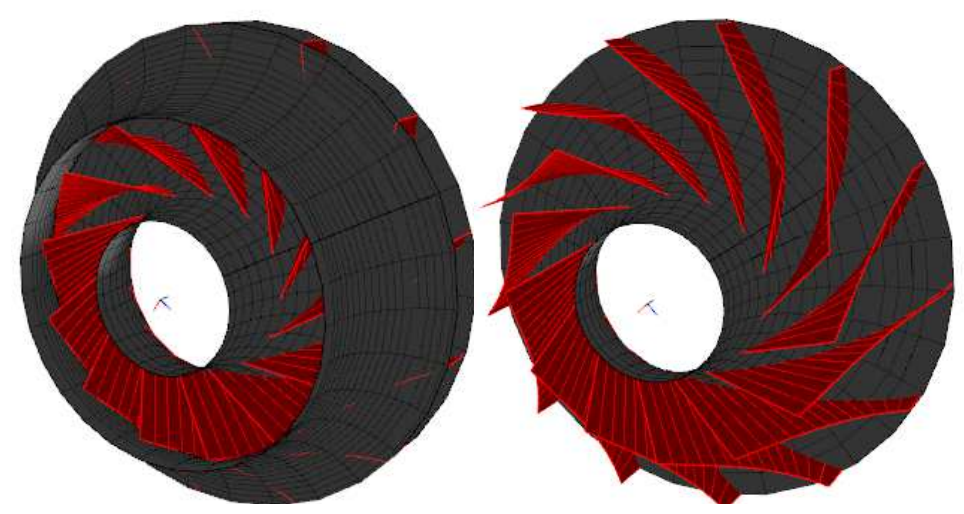

Figure 5: 3D Model of the Impeller According to the "Impeller 3D" Program.

2D impellers are constructed with blades shaped with a circular arc or profiling mean line (figure 6).
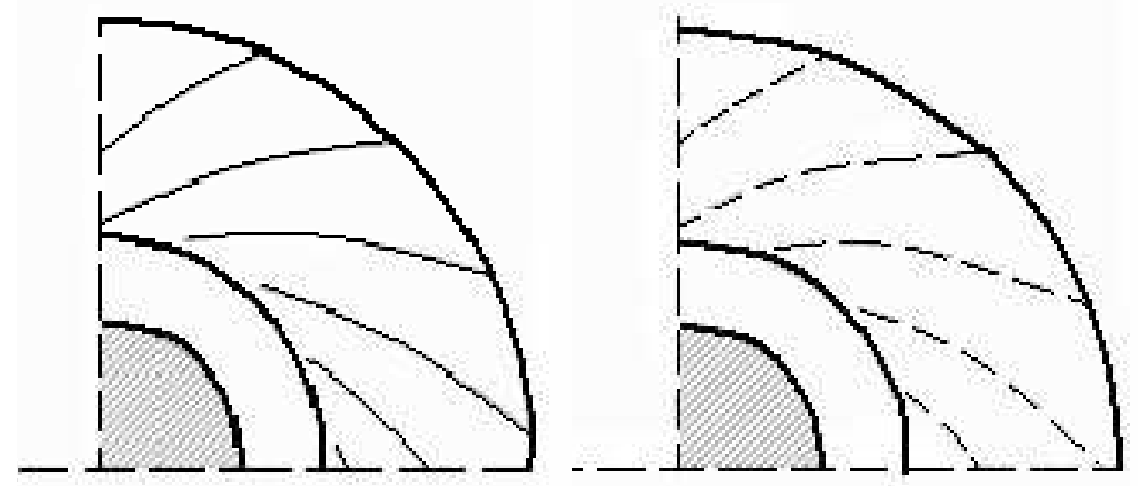

Figure 6: 2D Impeller with arc (Left) and Profiled (Right) Blades [0].

Classic design provides for the circular arc mean line. The circuit is shown in Figure 6 on the left.

The values of the curvature radii $R_{b l}$ and the position of the radii curvature center $R_{0}$ are determined by the diameters of the beginning $D_{1}$ and end $D_{2}$ of the blades and, and the angles of the blades at the inlet $\beta_{\text {bl1 and outlet }}$ 
$\beta_{\mathrm{bl} 2}$ :

$$
\begin{aligned}
& \bar{R}_{b l}=R_{b l} / D_{2}=\frac{1-\bar{D}_{1}^{2}}{4\left(\cos \beta_{\mathrm{bl} 2}-\bar{D}_{1} \cos \beta_{b l 1}\right)} \\
& \bar{R}_{0}=R_{0} / D_{2}=\sqrt{0.25+\bar{R}_{b l}^{2}-\bar{R}_{b l} \cos \beta_{b l 2}}
\end{aligned}
$$

From the formulas it follows [0]:

if $\cos \beta_{b l 2}>\bar{D}_{1} \cos \beta_{b l 1}$ the radius of blades curvature is positive, i.e. the center of curvature is located on the suction side of the blades. Usually the value of the inlet relative diameter $\bar{D}_{1}$ lies in the range of $0.52 \div 0.58$, and the inlet angle of the blades $\beta_{b l 1}=25 \div 30^{\circ}$. Therefore, usually the center of blades curvature is located on the suction side of the blades if $\beta_{b l 2}<58 \div 63^{\circ}$. These are the so-called "backward curved blades";

$$
\text { if } \cos \beta_{b l 2}=\bar{D}_{1} \cos \beta_{b l 1}, \beta_{b l 2} \approx 60^{\circ} \text { the blades curvature radius is equal to infinity, i.e. the blade mean line is }
$$
a straight line - "straight blades";

if $\cos \beta_{b l 2}<\bar{D}_{1} \cos \beta_{\text {bl1 }}$ the blades curvature radius is negative, that is, its center is located on the pressure side of the blades. For typical 2D impellers, this occurs if $\beta_{b l 2}>58 \div 63^{\circ}-$ «forward curved blades».

Arc blades are unsuitable for low-pressure, low-flow 2D impellers, since the blades are too long and the outlet sections of the blades are not loaded. For medium flow rate 2D impellers, arc blades, taking into account the peculiarities of the choice of the meridional form by the Universal Modeling Method, can be effective. Such 2D impellers have found application in a number of projects of the scientific team - for example, in the project of a $32 \mathrm{MW}$ linear pipeline singlestage compressor with very high efficiency $[13,14]$. But at high loading factor, the "geometric" shape of the blades, as a rule, leads to a high load and high local velocity at the beginning of the suction side of the blades. This leads to the formation of a wake with large mixing losses.

An alternative is the choice of the shape of the blades mean line with variable curvature (Figure 6 on the right). Reducing the radius of mean line curvature reduces the blade load.

In 2D impeller, the type of dependence $\beta_{b l}=f(r)$ determines the distribution of the load. For the convenience of design, an analytical dependence is introduced. The blade is divided into two sections, on each of which the dependence $\beta_{b l}=f(r)$ is parabolic:

$$
\beta_{b l i}=\beta_{b l 1}+A\left(\beta_{b l 2}-\beta_{b l 1}\right)\left[1-\left(1-\frac{\overline{r_{i}}-\bar{r}_{1}}{B\left(\bar{r}_{2}-\bar{r}_{1}\right.}\right)^{2}\right],
$$


$\beta_{b l i}=\beta_{b l 1}+A\left(\beta_{b l 2}-\beta_{b l 1}\right)\left\{1-\left(1-\frac{1}{A}\right)\left[\frac{\left(\bar{r}_{i}-\bar{r}_{1}\right)-B\left(\bar{r}_{2}-\bar{r}_{1}\right)}{(1-B)\left(\bar{r}_{2}-\bar{r}_{1}\right)}\right]^{2}\right\}$.

Coefficient "A" sets the amount of change in the blade angle in the first section of the blade:

$A=\frac{\beta_{b l b o r}-\beta_{1}}{\beta_{b l 2}-\beta_{b l 1}}$

Coefficient "B" sets the ratio between the first and second sections of the blade:

$$
B=\frac{\bar{r}_{b l b o r}-\bar{r}_{1}}{\overline{r_{2}}-\bar{r}_{1}}
$$

The smaller the "A" factor and the larger the "B" factor, the more the load is shifted towards the blade tip.

For 3D impellers, blades are constructed with mean line profiling according to the geometric or gas-dynamic method (Figure 7).

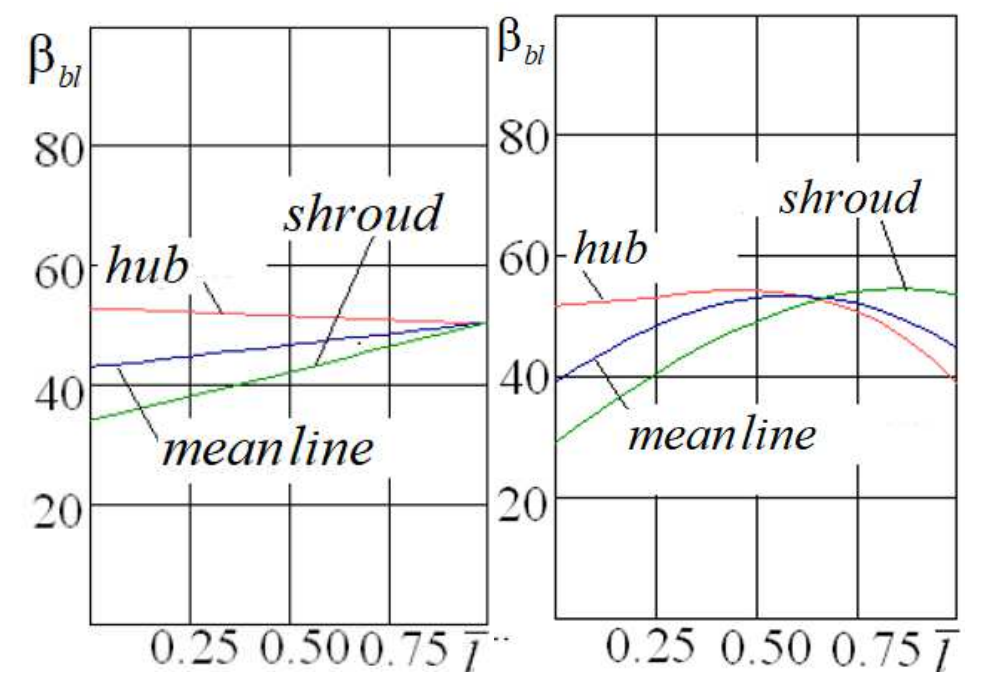

Figure 7: Changing the Blades Angles of the 3D Impeller with a Geometric

(Left) and Gas-Dynamic (Right) Method of Mean Line Profiling.

The functionality of the program allows the user to change the size of the blade row, compare the resulting blade options with each other in terms of blade area, bulk angle, etc. The parameter of the bulk angle is important for the possibility of manufacturing the impeller, as well as for assessing the flow area of the inter blade channel.

Sets the blade shape on the hub and shroud. The generatrix of the blade body is a straight line connecting the corresponding points of the profile on these surfaces.

As a result, the user receives the coordinates of the impeller blade and its meridian contour (Figure 8), which can be used in various $\mathrm{CAD}$ systems. 


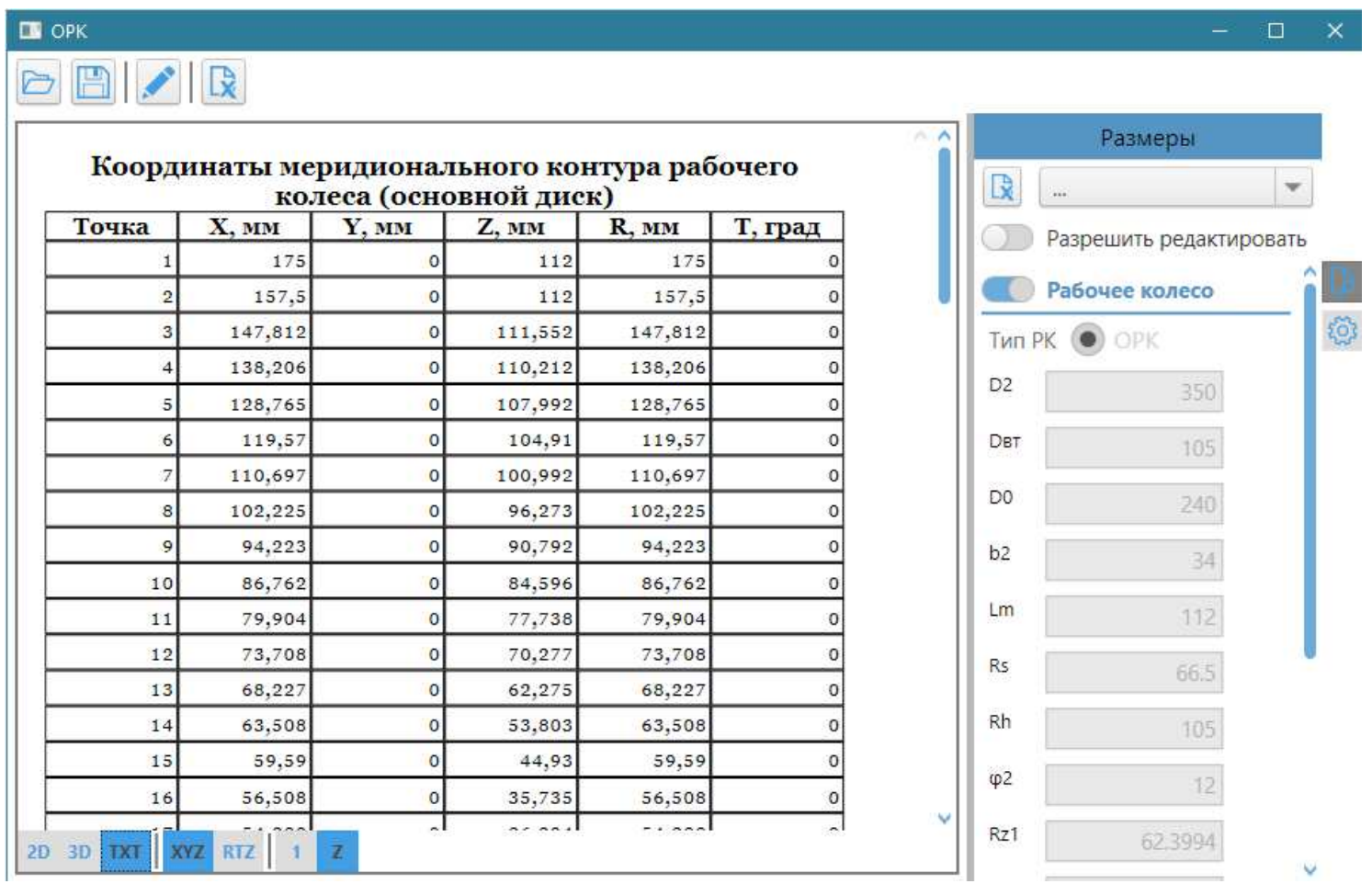

Figure 8: An Example of Impeller Coordinates Information Transmitted to the user from the "Impeller 3D" Program.

The user is also provided with graphs of changes in the coordinates and angles of the mean line and surfaces of the blades on the hub and shroud (figures 9 and 10).

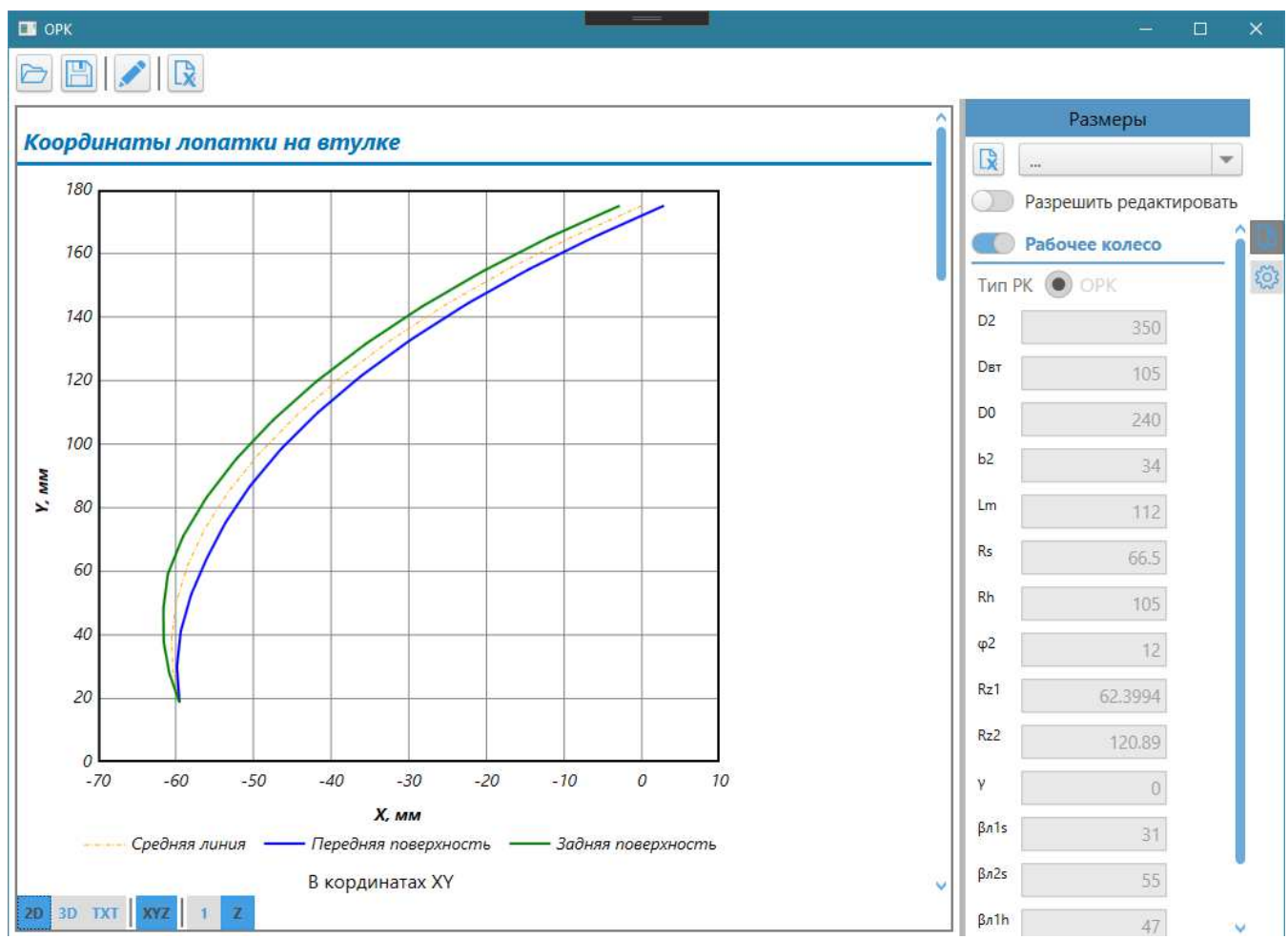

Figure 9: Coordinates of the Blade at the Hub. 


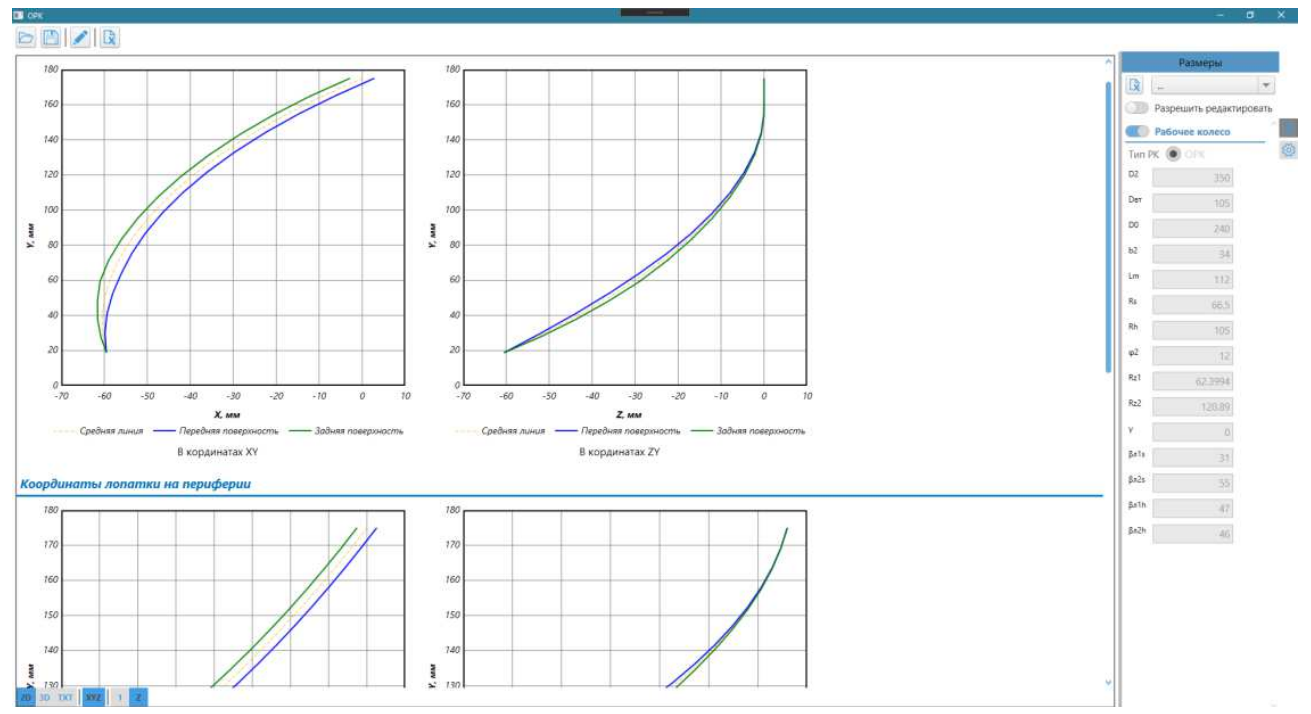

Figure 10: Parameters of the Designed Impeller Blades.

\section{SOFTWARE FOR CENTRIFUGAL COMPRESSOR STAGE 3D MODEL BUILDING}

The last step of designed compressor stage visualization is the creation of a 3D model. For this, the final dimensions and coordinates of the impeller blades are transferred to the "3D-compressor" program. It automatically builds a solid model in Solid Works software. An example of a model is shown in figure 11.
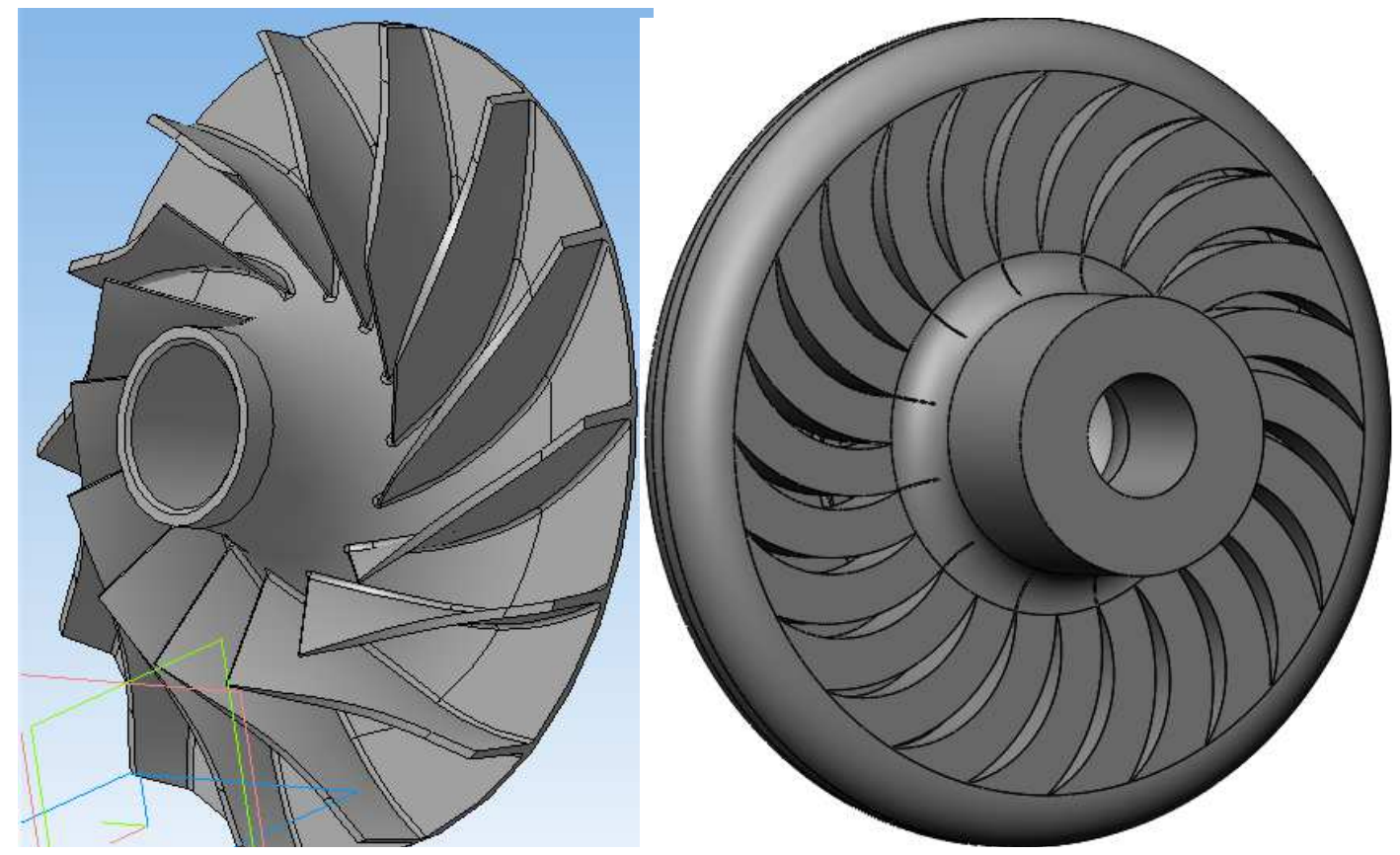

Figure 11: An Example of a Solid Model of the Designed Impeller (Left) and Return Channel (Right).

User-generated 3D models can be used for CFD calculations. In the future, it is planned to connect the software package of the Universal Modeling Method with CFD programs such as ANSYS.

\section{CONCLUSIONS}

The presented complex of visualization programs for the designed compressor stage is fully integrated into the programs for the optimal gas-dynamic design of centrifugal compressors and compressor stages and the calculation of their gas- 
dynamic characteristics of the Universal Modeling Method. This allows to quickly receive the information required by the customer in the form of drawings and 3D models.

\section{ACKNOWLEDGEMENTS}

The calculations were performed using the supercomputer of the center "Polytechnic" SPbPU. The study was funded by a grant from the Russian science Foundation (project No. 18-79-10165).

\section{REFERENCES}

1. Galerkin, Yu.B. Turbocompressors. [text] / Yu.B. Galerkin // Publishing house of KChT., 2010. - SPb. - 650 p.

2. Galerkin Yu.B., Rekstin A.F., Soldatova K.V., Drozdov A.A., Popov Yu.A. Development of the scientific school of turbocompressor engineering LPI-SPbPU, the results of cooperation with compressor builders. 17th International Scientific and Technical Conference. - Kazan. - 2017. - May. - p. 19-29.

3. Proceedings of the scientific school of compressor engineering SPbSPU. [text] / Edited by Yu.B. Galerkin // - M .. Ed. "SPbSPU". - 2010.

4. Galerkin, Yu.B. Modeling the workflow of industrial centrifugal compressors. Scientific foundations, stages of development, current state. Monograph. [text] / Yu.B. Galerkin, K.V. Soldatova // Publishing House of the Polytechnic University, 2011 .-P. 327.

5. Vasiliev, Yu.S. New generation highly efficient centrifugal compressors. Scientific basis of calculation, development of optimal design methods and production development. [text] / Yu.S. Vasiliev, P.I. Rodionov, M.I. Sokolovsky // Industry of Russia. 2000. - No. 10-11. - M. - p. 78-85.

6. Galerkin Yu.B., Rekstin A.F., Soldatova K.V., Drozdov A.A. Analysis of geometrical and gas-dynamic parameters of centrifugal compressor stages in a tenfold range of the calculated flow coefficient. Compressors and pneumatics. - 2016. - No. 7. - p. 32-43.

7. Galerkin, Yu.B. Modeling of gas-dynamic characteristics of centrifugal compressor stages with 3D impellers [text] / Yu.B. Galerkin, A.A. Drozdov // Scientific and technical bulletin of SPbSPU ._SPb., 2014 ._ No. 3 (202): Science and education .- p. 45-53: - (Mechanical engineering)._- ISSN 1994-2354 _-Bibliography: from. 45-53.

8. Galerkin, Yu.B. Design and optimization of a centrifugal compressor stage with an axial radial impeller using the engineering design method [text] / Yu.B. Galerkin, K.V. Soldatovs, A.A. Drozdov // Scientific and technical statements of SPbSPU .- SPb., 2015 ._No. 4 (231): Science and education ._P. 179-188: — (Mechanical engineering) ._ ISSN 1994-2354.

9. Galerkin Yu.B., Drozdov A.A. Issues of modeling the design mode of the impeller of a centrifugal compressor. - Science and education. Moscow State Technical University Bauman. - Electron. zhurn. - Moscow. - 2017. No. 07. P. 112-135. - DOI: $10.7463 / 0717.0001290$

10. Rekstin A.F., Drozdov A.A., Solovyova O.A., Galerkin Yu.B. Comparison of two mathematical models of a vaneless diffuser of a centrifugal compressor stage. Compressors and pneumatics. - 2019. - No. 1. - p. 2-10.

11. Rekstin A.F., Popova E.Yu., Utsekhovsky A.A. Analysis of the efficiency of centrifugal compressor stages using approximate algebraic equations. Compressors and pneumatics. - 2018. - No. 1. - p. 33-40.

12. Rekstin A. F., Bakaev B. V. Variant calculations of industrial centrifugal compressors based on a simplified mathematical model. // Scientific and technical statements of SPbPU. Natural and engineering sciences. 2018.Vol. 24, No. 4. P. 24-38. DOI: $10.18721 / J E S T .24403$ 
13. Galerkin, Yu.B. Highly efficient single-stage full-pressure compressor for gas compressor units (gas-dynamic design, result of model tests). [text] / Yu.B. Galerkin, A.F. Rekstin, K.V. Soldatova, A.A. Drozdov // Compressor and pneumatics. - 2014. - No. 8. - P. $19-25$

14. Smirnov, A.V. A new design of a highly efficient centrifugal compressor for the GPA-32 / 76-1.35 pipeline compressor stations. / A.V. Smirnov, V.G. Panenko, V.G. Gadyaka, V.P. Parafeinik, A.M. Borodenko // Compressors and pneumatics. - No. 3. - 2015. - P. 12-18

15. Drozdov, A. Rekstin Analysis of the velocity diagrams of impellers of centrifugal compressor stages after the preliminary design. - MATEC Web Conf. Volume 245, 2018. - International Scientific Conference on Energy, Environmental and Construction Engineering (EECE-2018). DOI 10.1051/matecconf/201824504004

16. Rekstin A.F., Galerkin Yu.B., Soldatova K.V. Computer programs application for development a primary design recommendations of low-flow rate centrifugal compressor stages. - Oil and Gas Engineering-AIP Conf. Proc. 2141. - Omsk. - Russia. - 2019, 030032-030032-10, https://doi.org/10.1063/1.5122082

17. Rekstin A.F., Galerkin Yu.B. The primary design method development of centrifugal compressor impellers based on the analysis of the geometrical parameters. - Oil and Gas Engineering- AIP Conf. Proc. 2141. - Omsk. - Russia. - 2019, 030052030052-10, https://doi.org/10.1063/1.5122102

18. Galerkin Yu.B., Rekstin A.F., Soldatova K.V., Drozdov A.A. Analysis of geometric and gas-dynamic parameters of centrifugal compressor stages in tenfold range of design flow rate. - Oil and Gas Engineering- AIP Conf. Proc. 2141. - Omsk. - Russia. 2019, 030018-030018-11, https://doi.org/10.1063/1.5122068

19. A.F. Rekstin, K.V. Soldatova, Yu.B. Galerkin, E.Y. Popova. Verification of a simplified mathematical model of centrifugal compressor stages. International Scientific and Technical Conference Smart Energy Systems, SES 2019; Kazan. E3S Web of Conferences 124 (2019) 01005. https://doi.org/10.1051/e3sconf/201912401007

20. Rekstin A.F., Soldatova K.V., Galerkin Yu.B. Experience of application the computer program based on a simplified mathematical model for industrial centrifugal compressors candidates. International Conference on Compressors and their Systems 2019. IOP Conf. Series: Materials Science and Engineering 604 (2019) 012045. doi:10.1088/1757$899 X / 604 / 1 / 012045$

21. Petukhov E.P., Galerkin Yu.B., Rekstin A.F. CFD-calculation method for vane diffusers of a centrifugal compressor stage International Conference on Compressors and their Systems 2019. IOP Conf. Series: Materials Science and Engineering 604 (2019) 012051. doi:10.1088/1757-899X/604/1/012051 (SCOPUS)

22. Nikiforov A.,Avramenko D.,Kuchumov A.,Terentev S.,Galerkin Yu.,Solovyeva O. Vaneless diffusers characteristics simulating by means of neural networks. International Conference on Compressors and their Systems 2019. IOP Conf. Series: Materials Science and Engineering 604 (2019) 012046. doi:10.1088/1757-899X/604/1/012046

23. Galerkin Yu.B., Rekstin A.F., Solovyeva O.A. Vaneless diffuser of the centrifugal compressor stage design method. - Oil and Gas Engineering- AIP Conf. Proc. 2141. - Omsk. - Russia. - 2019, 030007-030007-10, https://doi.org/10.1063/1.5122057

24. Rekstin A., Popova E., Ucehovscy A. Centrifugal compressor stages efficiency analysis by means of the approximate algebraic equations. - Oil and Gas Engineering (OGE-2018). - AIP Conf. Proc. 2007. - Omsk. - Russia. - 2018. - 030036-1-030036-11; https://doi.org/10.1063/1.5051897

25. Galerkin, Y. Mathematical modelling and analysis of an axial compressor supersonic stage impeller / Y. Galerkin, K. Soldatova, A. Rekstin // ICCMS 2018: 10th International Conference on Computer Modeling and Simulation. - Australia. Sydney. -Paper ID: 009. - 2018. P. 197-201 
26. Y. Galerkin, L. Marenina, Soldatova K. CFD wind tunnel tests of Centrifugal stage return channel vane cascades. ASME Gas $\begin{array}{llll}\text { Turbine } \quad \text { India } \quad \text { Conference. } & - & 2015 . & -\end{array}$ http://www.asmeconferences.org/GTIndia2015/PaperAccepted.cfm?noToolbar=yes. DOI: 10.1115/GTINDIA2015-1216.

27. Galerkin Y., Rekstin A., Soldatova K. Gas dynamic design of the pipe line compressor with 90\% efficiency. Model test approval. International Conference on Compressors and their Systems. London. City University. - UK. - 2015. http://iopscience.iop.org/article/10.1088/1757-899X/90/1/012044/meta. DOI: 10.1088/1757-899X/90/1/012044.

28. Galerkin Y., Soldatova K., Solovieva O. Numerical study of centrifugal compressor stage vaneless diffusers. International Conference on Compressors and their Systems. London. City University. - UK. $-2015 . \quad$ http://iopscience.iop.org/article/10.1088/1757-899X/90/1/012048/meta. 
